\title{
Language as a Tool for National Integration: the Case of English Language in Nigeria
}

\author{
Hanna Onyi Yusuf \\ Department of Educational Foundation and Curriculum, \\ Faculty of Education, Ahmadu Bello University, Zaria, Nigeria
}

\begin{abstract}
In multilingual societies like Nigeria, language which can be used as an effective instrument for national development and the promotion of national consciousness and unity can also be used as a weapon for marginalization and or exclusion. The latter trend can destabilize a nation as it sets different linguistic groups against each other in an attempt to fashion out an identity for themselves and express their existence and or relevance to the society. This scenario can be found in Nigeria, where language has been the sole factor in group integration and atimes, disintegration.

This paper addresses the language issues in Nigeria by exploring the unifying significance of the English Language in Nigeria. This unifying role and its allied issues are discussed in this paper with a view to showing that the imposition or adoption of any language apart from English as the Nation's official language will lead to a chain of sociopolitical crisis that could threaten the corporate existence of Nigeria. This paper suggests that the English language should continue to play its unifying role while we continue to develop and maintain our local indigenous languages.
\end{abstract}

\section{Introduction}

One of the dominant and pervasive problems Nigeria has and indeed Africa is the language issue. Language being a potent vehicle of transmitting culture, norms, values and beliefs from generation to generation remains a central factor in determining the overall status of a nation. This informs the submission of Isayev [10] that "language is a nation's most important asset. There is no such thing as a nation without a common linguistic basis". The dominant inference to Isayev's observation is that for national integration, cohesion and development to thrive, there must be language capable and acceptable by all in the administration/running of a nation's affairs.

In Nigeria, like most African Countries, multilingualism is commonplace. The problem of 'forging ahead', a situation in which languages compete among themselves and scramble for national recognition or official status, whether indigenous or foreign, always rears its head. Only one language must be the official language (the language of administration and education at some level), the language of relevance for unifying the nation. Fortunately or unfortunately, English has emerged as that privileged language without which the unity of Nigeria as a nation is most improbable, if not out-rightly impossible.

This paper attempts to highlight how the English language, among other functions in Nigeria, unites the country. Its unifying role and its allied issues are discussed with a view to showing that the imposition or adoption of any language apart from English as the nation's official language will lead to a situation as captured by Cob (cited in Igboanusi 2002): "if you insist, the union will be dissolved. It would mean that you have kindled a fire which all the waters of the ocean cannot put out, but which seas of blood can only extinguish".

Nigeria is a multilingual country where an estimated 505 languages are spoken of which Igbo, Yoruba and Hausa are the major languages with about 18 million speakers each. The British first introduced English in Nigeria with the establishment of trading contacts on the West African coast in the sixteenth century. This resulted in a form of Nigerian Pidgin, which probably is the predecessor of presentday Nigeria English Pidgin, which is mainly used for inter-ethnic communication. English began to be formally studied in Nigeria from the middle of the nineteenth century on. It now has a geographical spread throughout the country as is used in predominantly formal contexts such as government, education, literature, business, commerce, media, international communication and as a lingual franca in social interaction among the educated elite. It is treated as "the official language of the country" although there is no government statute or decree specifying this.

\section{Definition of Language}

Language is a symbol system based on pure or arbitrary conventions... infinitely extendable. Extendable and modifiable according to the changing needs and conditions of the speakers [18]

According to this definition, language is a symbol system. Every language (that exists in the written form) selects some symbols for its selected sounds. 
The English sound ( $\mathrm{K}$ for example has the symbol $\mathrm{K}$ while the Hindi sound $/ \mathrm{K} /$ has the symbol dh for it. These symbols form the alphabet of the language and join in different combinations according to a well laid out system to form meaningful words.

The system talked here is purely arbitrary in the sense that there is no one to one correspondence between the structure of a word and the thing it stands for. The combination p.e.n; for example stands in English, for an instrument used for writing. Why could it not be e.p.n or n.e.p.? There is nothing sacrosanct about the combination p.e.n except that it has now become a convention - a convention that cannot be easily changed.

As stated here, language conventions are not easily changed yet it is not impossible to do so. Language is infinitely modifiable and extendable. Words go on changing meanings and new words continue to be added to language with the changing needs of the community using it. Shakespeare, for example, used the word stomach to mean courage. Similarly, words like laser, sputnik, astronaut etc are of quite recent origin in English language.

According to Sapir [16], language is a purely human and non-instinctive method of communicating ideas, emotions and desires by means of a system of voluntarily produced symbols.

There are two terms in this definition that call for discussion: human and non-instinctive.

Language, as Sapir rightly said, is human. Only humans posses language and all normal humans uniformly possess it. Animals do have a communication system but it is not a developed system. That is why language is said to be speciesspecific and species-uniform.

Also, language does not pass from a parent to a child. In this sense, it is non-instinctive. Children have to learn language, and he or she learns the language of the society he is born into.

According to Brown [4], language is the institution whereby humans communicate and interact with each other by means of habitually used oral-auditory arbitrary symbols.

This definition rightly gives more prominence to the fact that language is primarily speech produced by oral-auditory symbols. A speaker produces some string of oral sounds that get conveyed through the air to the speaker who, through his hearing organs, receives the sound waves and conveys these to the brain that interprets these symbols to arrive at a meaning.

To Noam Chomsky [5], language is a set of (finite or infinite) sentences. Each finite in length and constructed out of a finite set of elements.

Chomsky meant to convey that each sentence has a structure. The human brain is competent enough to construct different sentences from out of the limited set of sounds symbols belonging to a particular language. Human brain is so productive that a child can at any time produce a sentence that has never been said or heard earlier.

Richard and Platt [15] defined language as a system of arbitrary vocal symbols used for human communication, while Wilson [17] views it from another angle. To them, language is a system of arbitrary vocal symbols by means of which a social group cooperates.

Both definitions above prominently point out that language is a system. Sounds join to form words according to a system. The letters c, r, a, v, e, join to form a meaningful word crave, whereas combination like v, e, r, a, c, or ravec do not form any meaningful combinations.

In the formation of words, convention makes them part of a system. Words also join to form sentences according to these systems. A sentence like: (I like oranges) is accepted but one cannot accept a string of words like (like oranges i). It is in line with this school of thought that language is believed to be a system of systems.

Encyclopedia Britannica [6] explains that language is a system of conventional spoken or written symbols by means of which humans, as members of a social group and participants in its culture communicates.

Generally, therefore, language is seen as a system of communication used by humans in a specific linguistic community (society).

\section{Characteristics of Language}

Language has certain features. They include language as a means of communication, its arbitraries, as a system of systems, as a purely human phenomenon, as primarily vocal and as a form of social behavior etc.

On the other hand, the properties of language are that language is creative, structured, meaningful, referential and interpersonal.

\section{The National Language Issue}

The amalgamation of the northern and southern protectorates of Nigeria in 1941 by the British colonial administrators lumped together people of diverse ethnic, cultural and linguistic backgrounds into what has now become the Federal Republic of Nigeria with over four hundred mutually unintelligible linguistic groupings. According to Ayo Bamigbose, one of Nigeria's foremost linguists, Nigeria epitomizes a barbaric scenario. In most cases, linguistic groupings correspond to ethnic groupings making Nigeria about the ethnically diverse country in Africa.

Given the problem often associated with ethnic diversity, it is not surprising that adopting an indigenous Nigerian language as lingua franca become a major preoccupation among Nigerian 
linguists, language planners and the government in the 1970s and 80s. Since linguistic homogeneity (often) entails nationism (which accounts for why people would first give up their lives before their languages), an indigenous national language was seen as one way of ensuring the continued oneness, or national integration, of the many ethnic groupings that makes up the country. This is because each local language is intimately related to or equates an ethnic group, thus the use of a local language reinforces attachment to ethnicity thereby going against the current of national sentiment.

However, the adoption of a national language for Nigeria, and indeed any multilingual society, is a volatile issue. Several proposals were considered for Nigeria. The most widely debated is the adoption of one of the three major languages (Hausa, Igbo and Yoruba) as the national language. The problem, of course, become determining the criteria for adopting one over the others. One (not too) incontrovertible criteria for this choice would be language dominance. However, Myers-Scotton, a well-known sociolinguist noted, one of the reasons for official language dilemma in Africa is that there is usually no single group with both enough numerical and political dominance over the others to make its language the natural choice. This is exactly the case in Nigeria. Thus, English was adopted.

\section{English as a Unifying Tool for National Integration in Nigeria}

English as a Unifying Tool for National Integration in Nigeria

Of the entire heritage left behind in Nigeria by the British at the end of colonial administration, probably, none is more important than the English Language. It is now the language of government, business and commerce, education, the mass media, literature, and much internal as well as external communication.

English language is the most important language of the world being the first language of the United Nations and arguably the only language spoken in all nations of the world. English helped in promoting, nurturing and uniting the Nigerian nation over the years and even now.

English can be said to be the language of integration in Nigeria. Amidst the compounding complexity of Nigeria especially in relation to the language question, the only language that indexes the spirit of togetherness is English. More often than not, activities conducted in indigenous languages are reprobated as being ethnic or tribal, except in cultural celebrations or entertainment displays. This explains why even during the first republic and even the colonial era, when English had not attained its present level of ascendancy in national and international affairs, political parties were formed in
English. However, the parties might have regional bases; the fact that they were named in English entailed their collective import. The Northern People's Congress (NPC), the Action Group (AG), the NCNC (National Council of Nigeria Citizens, after the excision of Southern Cameroon), National Elements Progressive Union (NEPU) e.t.c were formed to integrate all Nigerian and give them a sense of belonging. This trend has necessarily survived until today with all the national political parties formed and sloganeered in English.

This integration role is not limited to politics or political parties alone but virtually all strata of Nigerian life. In sports, the function of English as its language gives room for integration, as it remains the only area where the syndrome of ethnicity/tribalism has not permeated. Most Nigerians do not care whether the national team is made up of members of the same family, not to talk of an ethnic group, as long as they can deliver the goods or goals. The use of English facilitates the absence of ethnic sentiments in this regard,

English is also acceptable to all - even to those who clamour against its irresistible dominance. The language is not fraught with suspicions in any formal or literate context. It is the only language that does not generate suspicions of having a skeleton in one's cupboard or a 'hidden agenda' in inter-ethnic relationship or transactions.

English also serves as the language of nationism, concerned with political integration and efficiency [3].

The language brings all the supposed 'nations' of Nigeria to function as one. Mention is often made of each ethnic group being a nation on its own with the Hausa nation, the Igbo nation, the Yoruba nation, the Edo nation, Jukunland, Tivland, Urhoboland, Ogoniland, Ebiraland etc. as examples. However, the cohesion of all under the subsuming Nigerian nation is possible through English. In other words, without English, the ubiquitous violent ethnic groups like Oodua People Congress (OPC) Egbesu Boys, The Arewa People's Congress (APC) Ijaw Youth Solidarity (IYS), Bakassi Boys, and other militant groups would have found more justification for desiring to secede from the Nigerian federation.

Ironically, it is also the language of nationalism. This is because the love for the country as a whole has to be manifested through the language intelligible to all and sundry, lest the 'ethnic agenda' be implicated. This reason accounts for why nationalists like Herbert Macaulay, Obafemi Awolowo, Ahmadu Bello, Nnamdi Azikiwe had to use English language as a weapon of nationalist struggle. A nationalist bases his patriotic views in English. If English is not used to express the same ideas fo which he is known as nationalist, he becomes an ethnic jingoist or a tribal apologist. It is the language of authenticity in Nigeria today. 
As a Language of Wider Communication (LWC), English is used for phatic communion, ceremonial purpose, and instrument for keeping records, information dissemination, self-experiment and embodiment of thought among the various linguistic groups of Nigeria. English provide the common linguistic basis that constitutes a requisite for the existence of any nation. Therefore, with English as the common tongue to all the ethnic groups, the collective sentiment of belonging together despite the individual or ethnic differences is forged.

Related to the roles discussed is the fact that Nigerianism or collective identity is stamped on national institutions through the medium of English. The army, the navy, the air force and the police that all safeguard the territorial integrity of, and peaceful existence in, Nigeria are controlled with English (unadulterated or adulterated - pidgin). The National Youth Service Corps (N.Y.S.C) is aimed at bringing together Nigerian Youths with a view to reinforcing the sentiment of oneness. The constitution of Nigeria is written in English to create a level ground for all Nigerians to play, though the meta-language for the teaching of the three language and their legislative terms was being developed (at a time in the past) in the three major languages.

Writing in English by Nigerian literary artists has also created a distinctive Nigerian literature marked by its own characteristics imbued with features of inter-cultural communication and cooperation. English is also the language of international relations and diplomacy - the language that mirrors Nigeria to the world. All these have the effects of reducing what Adegbite [2] refers to as "deep-rooted mutual suspicious that result in prejudice, stereotypes and subtle linguistic hostility among various linguistic groups." And in fact, there are obvious national symbols such as National Flag, The National Anthem, The National day/independence day, the national associations as well as several national monuments of which are designed in English and all of which 'assert' that English is the foundation of the magnificent structure called Nigeria. If English is removed, it is feared that the whole nation may automatically crumbles.

\section{English versus Indigenous Languages: Towards A United Nigeria}

There have been argument and counter-arguments for and against the issue of English language as the official language/language of education in Nigeria. Fanilola, [8] opined that, rather than solving the issue, it is becoming more problematized at the level of finding an attractive candidate to replace it by scholars as each suggestion is fraught with controversies. When Hausa, Ibo Yoruba are being stoutly resisted since 1961 when parliament debated national language question, till date (as evident in Enahoro, [19], the minority languages have no candidate as population is a key factor in language planning. The suggestion of pidgin or the hybrid 'Wazobia' and such unrealistic alternatives is also riddled with more complex problems.

In a situation like this, it is obvious that English becomes increasingly important. The volatile Nigerian socio-political domain requires English now, more than ever before, to avoid disintegration and threat to its corporate existence. Though, one is uncomfortable with the negative sides of English as it 'masterminds' the relegation of the Nigeria languages to the extent that we do not have a real language policy, instantiates the systematic loss of Nigerian cultural identity among the younger generation and ensures the consolidation of colonial legacy, yet there is no any other language that can keep Nigeria one apart from English. The 'war against English' in some quarters is thus a lost battle. English has already been nativised and the challenge is not standardization of Nigerian English - making simple the variety of English that is marked by local aura at all levels of linguistic analysis: phonology, morphology, syntax, lexico-semanties and pragmatics but efforts should be geared towards developing and promoting Nigerian Language (s) as national heritage. It is agreed, but English should not be de-emphasized at all for Nigerians to be able to function well, acceptably and intelligibly, in the fast constricting modern world and in fact, to survive as a nation. The utilities of English need not be undermined for promoting Nigerian unity.

Although a united Nigeria rests on English, yet her survival as a nation is beyond English. Nigeria is just a 'nation on paper' as Professor Wole Soyinka was frank to say because of her inherent contradictions - Ours is:

A nation where its public sector is grossly inept, inefficient, dogmatic, arrogant, unpatriotic, erratic, incorrigible, corrupt, abusive, lackadaisical, abrasive and irredeemably over bureaucratic [20]. A nation where the law enforcement system is actively obsolete, illiterate, myopic, robotic, bigotic, anarchrontic, corrupt, suspicious, unprogressive, schizophrenic, prodigacious, psychologically inferior, unimaginative, intellectually porous, academically jealous and pessimistic.

A nation where her leadership has more glorification of the old order of carnivorous feudalism, god-fatherism, mafianism, cabal tribalism, traditional rulership of royal blood hegemony and patron of serfdom.

For Nigeria to survive as a real nation, the problems identified have to be properly addressed. The demand for constitutional reforms has to be met to create justice and equity in the distribution and administration of resources. The call for a national conference to determine the basis of togetherness 
should be heeded so that the tension that pervades Nigeria and the problems of political bickering, economic sabotage, social unrest, educational backwardness, development deficit, corruption and graft, mis-govenance, indiscipline, unemployment, poverty, injustice and other social tragedies that besiege Nigeria and threaten her unity - far beyond English but which will be expectedly addressed in English - will be tackled.

\section{Importance of the English Language}

Language is something specific to humans, that is to say it is the basic feature that distinguishes humans from all other living beings. Language therefore remains potentially a communicative medium capable of expressing ideas and concepts as well as moods, feelings and attitudes.

A set of linguists who based their assumptions of language of psychology made claims that language is nothing but habit formation. According to them, language is learnt through use of language, the better one learns.

Written languages use symbols (characters) to build words. The entire set of words in the language's vocabulary; the ways in which the words can be meaningfully combined is defined by the language's syntax and grammar. The actual meaning of words and combinations of words is defined by the language's semantics.

The latest and the most advanced discoveries and inventions in science and technology are being made in the universities located in the United States of America where English Language is the means of scientific discourse.

The historical circumstances of India (having been ruled by the British for over two centuries) have given the Indians an easy access to mastering English language and innumerable opportunities for advancement in the field of awards for creative and comparative literatures during the last few years. Sometime ago, an Indian author, Arundhati Roy, won the prestigious booker prize for her book "The God of small Things", Her book sold volumes of copies all over the globe.

Over the years, English language has become one of our principal assets in getting a global leadership for books, written by Nigerian Author and for nollywood films in English language. Several Nigerian films have got several nominations for Oscar Awards. It does not require any further argument to establish the advantage English language has brought to us at the international level.

English language comes to our aid in our commercial transactions throughout the globe. English is the language of the latest business management in the world. English is a means not only for international commerce; it has become increasingly essential for inter-state commerce and communication.

A language attracts people because of the wealth of literate and knowledge enshrined in it. English poses no danger to Nigerian languages. The Nigerian languages are vibrant and are developing by the contributions of great minds using them as their vehicle of expression. English is available to us as a historical heritage in addition to our own language. We must make the best use of English to develop ourselves culturally and materially so that we can compete with the best in the world of mind and matter. English language is our window to the world.

English language is one tool to establish our viewpoint. We can learn from other's experiences. We can check the theories of foreigners against our experience. We can reject the untenable and accept the tenable. We can also propagate out theories among the international audience and readers.

Generally, Standard English today does not depend on accent but rather on shared educational experience, mainly of the printed language. Presentday English is an immensely varied language, having absorbed material from many other tongues. It is spoken by more than 300 million native speakers, and between 400 and 800 million foreign users. It is the official language of air transport and shipping; the leading language of science, technology, computers and commerce; and a major medium of education, publishing, and international negotiation. For this reason scholars frequently refer to its phase as World English.

\section{The National Language Question}

Given the problems often associated with ethnic diversity, it is not surprising that adopting an indigenous Nigeria language as lingua franca became a major preoccupation among Nigerian linguist, language planners and the government in the 1970s and 80s. Since linguistic homogeneity (often) entails nationism (which accounts for why people would first give up their lives before their languages), an indigenous national language was seen as one way of ensuring the continued oneness, or national integration, of the many ethnic groupings that make up the country. Many believe differences between indigenous languages keep the people apart, perpetuate ethnic hostilities, weaken national loyalties and increase the danger of separatists sentiments. This is because each local language is intimately related to or equates an ethnic group, thus the use of a local language reinforces attachment to ethnicity thereby going against the current of national sentiment.

However, the adoption of a national language for Nigeria, and indeed any multilingual society, is a volatile issue. Several proposals were considered for Nigeria. The most widely debated is the adoption of 
one of the three major languages (Hausa, Igbo and Yoruba) as the national language. The problem, of course, became determining the criteria for adopting one over the others. One (not too) incontrovertible criterion for this choice would be language dominance. However, as Myers Scotton a wellknown sociolinguist noted, one of the reasons for official language dilemma in Africa is that there is usually no single group with both enough numerical and political dominance over the others to make its language the natural choice. This exactly the case in Nigeria.

It is then this difficulty in choosing an indigenous language as the official language that has resulted in the continued existence of English as the official language of education and administration in Nigeria long after the colonial circumstances that gave rise to it has been dismantled. English is considered acceptable to be official language by many because of its neutrality. Therefore, most people would rather we let the sleeping giant lie.

In addition to its neutrality, the social and political elite who are generally highly educated in colonial language have a major stake in its propagation since its continued use allows them a major share of lucrative jobs and advances their social position and power. The same can be said of the developed nations, especially the ex-colonial masters since the continued use of the colonial language provides a good market for their products.

Given all the problems associated with adopting an indigenous national language, the questions must be raised as to whether it is really worth it. Why not just continue with the language of the colonial masters as in other African Countries notably Ghana (English), Cameroon, (English and French), Angola (Portuguese), Zambia (English), Zimbabwe (English), and Mauritania (French) to mention a few. Is there more national unity in Somalia where there is one indigenous national language (Somali) in addition to Arabic? Is the continued use of colonial language really an indication of imperialism? How does an indigenous national language affect Nigeria's relationship with the West? There are similar questions that have cropped up in the past debates on the issue. One cannot pretend to have the answers.

\section{English language in the Multilingual Nigeria Context}

Multilingualism is a situation in which two or more languages operate within the same context (Ndimele, 2003). Factors such as political annexation marital relation, economic transaction, cultural association, educational acquisition and religious affiliation bring about multilingualism.

The advent of English colonialists in the 18th Century brought about linguistic imperialism, a situation in which according to Asne as cited in Fanilola [8] . "The minds and lives of the speakers of a language are dominated by another language to the point where they believe they can and should use only the foreign language when it comes to transaction dealing with the advanced aspects of life such as education, philosophy, literature, government, the administration of justice". When Nigeria attained her political independence in 1960, this has to be sustained for her interest. This is because there was no indigenous language that could perform the function of English because of the mutual suspicion of, and ethnic consciousness among virtually all Nigerians. At the height of it all, the truth was revealed about the new state of the nation that no indigenous language is acceptable for all Nigerians. This view as captured by Nida and Wonderly (1971:65) "In Nigeria, there is simply no politically neutral language. Infact, the division into three major regions reflects the three poles: Hausa, Igbo, Yoruba. The political survival of Nigeria as a country would even be more seriously threatened that is if any of these three languages were promoted by the government as being the one national language.

\section{The meditative role of English Language}

In the face of the multilinguistic crisis in Nigeria, English language should play the role of mediation. According to Obausi [14], a common language is a mark of identification and a necessary powerful tool for unity for national consciousness - nationalism. We need a common language. We should allow English unite us by accepting it like the views of Adegbite [2] which supports our views here that, "English should serve an expected coordinating role as a means of interethnic and international communication..."

Another chief reason why English should serve as a mediator between people of different ethnic languages in Nigeria is according to Adebayo [1] because the youths who are mostly cosmopolitan by birth, with usually mixed identity and who suffer, for no fault of theirs, from this unclear identity in quest for social mobility vent out their anger at a federation that cares for them.

A knowledge of English is thus an indispensable requirement for anyone to rise or live in any place under the context of the community no matter the variety of the English. By this we mean varieties which have been influenced according to goal, geographical dispensation and mother tongue. It is this local texture of English language that provides the in-going and out-going varieties for inter-ethnic communication and gives the individuals the sense of oneness, unity and loyalty. Even the formal English as taught and learnt in formal settings (classrooms) 
invariably have the local texture - not used as the English man uses it.

Language is dynamic - lives and grows. The tones and pronunciation of native speakers are different resulting to dialects and eventual isoglosses. Even connotations of words acquire strength as the uses go depending on use and environment, not to talk of placement of stress shift.

In vocabulary and grammar, we use certain styles such as calquiring - a method of translating our expressions as is usual without indigenous languages e.g., Headtie (scarfs) describing the piece of cloth tied on the head.

- 'bush meat' for game

- 'machine' for motorcycle

- 'chewing stick' for piece of stick chewed for cleaning teeth etc.

There are other forms of transliteration and mother tongue influence that give Nigerian English new words and or add meaning to existing ones e.g.

- He is a bush man - $\mathrm{He}$ is unrefined

- Give me my change - $\quad$ Can I have my balance?

- He impregnated the girl - $\mathrm{He}$ put the girl in a family way etc.

The major function of language is communication and social identity for human co-existence. Because language is dynamic, growth of any language can lead to birth of a new one. Nigerian English is a domesticated nativized variety. This variety is bound to have peculiarities according to the socio-cultural and political environment.

English is our new historical symbol of federalism and nationalism and so, let us incontestably use it for the Nigeria nation. So, let us domesticate it and get integrated.

\section{Conclusion}

In conclusion, this paper has examined how English functions as the language of unity in Nigeria and forms the basis of the nation's linguistic existence. It is contended that with controversies surrounding the adoption of any of the Nigerian languages and the grave implications such adoption engenders, English Language saves the day as the nation's lingua franca. It integrates all Nigeria as a cohesive entity, it is acceptable to all (to some grudgingly), and it serves the purpose of nationism and nationalism at the same time as it lessens the feelings of perceived intra-national linguistic domination by majority groups.

For the unity of Nigeria to be sustained, it is ultimately suggested that the English language must continue to play its unifying role for the essentially necessary national integration while we continue to develop and maintain our local languages so as not to destroy the beauty of our natural endowment and heritage.

\section{References}

[1] Adebayo, A.J. (2003) Language, National Integration and the Nigeria Federation.

[2] Adegbite, W. (2004) Bilingualism-Biculturalism and the utilization of African Languages for the Development of African Nations. Ibadan: Hope publications Ltd.

[3] Bamgbose, A. (1991) Language and the Nation: The language question in sub-Saharan Africa. Edinburg: Edinburgh University Press.

[4] Brown, H.D. (1987) Principle of language learning and teaching. Englewood Cliffs, NJ: Prentice Hall.

[5] Chomsky, N. (1957) Language: The properties of Human Language. U.S. Department of Education press.

[6] Encyclopedia Britannica (2002) Vol 23. Cambridge: Cambridge University Press.

[7] Eno-Abasi, E.U. (2003). Tonal Reconstruction in Eastern lower cross dialects. Portharcourt: The Linguistic Association of Nigeria.

[8] Fanilola, K. (1988) "Education through foreign language in Nigeria: Problems and Prospects". Alore: Ilorin Journal of Humanities; vols 3 \& 4. pp 70-92.

[9] Igboanusi, H. and Ohia, (2001) "Language conflict in Nigeria: the prospects of linguistic minorities". Language Attitude and language conflict in West Africa. Ibadan: Enicrownfit publishers. pp. 124-142.

[10] Isayev, M.I. (1977) National Language in the USSR: Problems and Solutions. Moscow: Progress Publications.

[11] Manivannan, G. (2006) "Importance of English", Global Journal of Humanities, Vol. 3 (1\&2). Online.

[12] Ndimele, O.M. (ed) (2006) Four Decades in the study of languages and linguistics in Nigeria: A festschrift for Kay Williamson. Aba: National Institute for Nigerian Languages.

[13] Nida, E. and Wonderly, W.L. (1971) "Communication Roles of Languages in Multilingual Society". Language use and social change. London: OUP for international Africa Institute. pp 57-74.

[14] Obuasi, I. (2006) The place of language in Nigeria's Reform Agenda. Nsukka: UNN Press Ltd.

[15] Richard, J.C; Platt, J. \& Platt, H. (1992) Longman dictionary of language and applied linguistics. New York: Rechards Earley.

[16] Sapir, L. (1921) The meaning of language, theory and practice. Washinton D.C. U.S.A centre for Applied Linguistics. 
[17] Wilson, J. (1986) "Task-based language learning". ESP for the University (pp22-43). Oxford: Macmillan Education.

[18] Yule, G. (1985) The study of language. Oxford: Oxford University Press.

[19] Enahoro, A. (2002) "Towards a new constitutional order" in Vanguard. Lagos: July 5. ppp18-19.

[20] Oladesu, E. (2002) "Revisiting the mistakes of the founding fathers". The Comet. Lagos: October 2; pp 14-15. 